\title{
Bilateral Femoral Neck Stress Fracture in Child: A Case Report
}

\author{
Gun-Woo Lee, MD, Kyung-Soon Park, MD, PhD, Taek-Rim Yoon, MD, PhD, \\ Eshnazarov Kamolhuja Eshnazarovich, MD* \\ Center for Joint Disease, Chonnam National University Hwasun Hospital, Hwasun, Korea, \\ Departments of Traumatology, Neurosurgery, and Military Field Surgery, \\ Samarkand State Medical Institute, Samarkand, Uzbekistan*
}

A femoral neck stress fracture in child is rare, particularly in bilateral case. It is easy to miss initially or may be misdiagnosed. The authors experienced a case of bilateral femoral neck stress fracture in a 10-year-old boy with bilateral hip. The patient was successfully healed by conservative treatment. We report this rare case with a review of the literature. A femoral neck stress fracture should be included in the differential diagnosis in children who present with sustained hip or groin pain.

Key Words: Femur neck, Stress fractures, Child, Bilateral

Stress fractures in children are commonly reported in the tibia, fibula, femur and metatarsals, and femoral neck stress fractures are rare ${ }^{1}$. Femoral neck stress fractures occur mainly in athletes, military trainees, physically hyperactive people, and patients with metabolic disorders or who are undernourished ${ }^{2}$. Since Devas $^{3)}$ first described cases of femoral neck stress fractures in children and classified the fractures into two types in 1963, only about 20 cases have been reported ${ }^{1,3,4)}$.

Femoral neck stress fractures are easy to be

Submitted: April 11, 2016 1st revision: June 23, 2016

2nd revision: August 18, 2016 Final acceptance: August 19, 2016

Address reprint request to

Kyung-Soon Park, MD, PhD

Department of Orthopedic Surgery, Center for Joint Disease, Chonnam National University Hwasun Hospital, 322 Seoyang-ro, Hwasun-eup, Hwasun 58128, Korea

TEL: +82-61-379-7677, 7676 FAX: +82-61-379-7681

E-mail: chiasmalahanmail.net

This is an Open Access article distributed under the terms of the Creative Commons Attribution Non-Commercial License (http://creativecommons. org/licenses/by-nc/4.0) which permits unrestricted non-commercial use, distribution, and reproduction in any medium, provided the original work is properly cited misdiagnosed as a hip joint sprain or synovitis in children because of their rareness in skeletally immature children and the nondescript features in the early stage.

\section{CASE REPORT}

A 10-year-old boy, $147 \mathrm{~cm}$ tall and $40 \mathrm{~kg}$ weight, presented to our hospital with complaint of sustained bilateral hip pain for 4 weeks. The pain was getting worse while walking and spread throughout thigh. $\mathrm{He}$ showed positive sign of Patrick's test in bilateral hip and a slight limping gait and limited range of motion (ROM) on a physical examinations. The pain was relieved with rest and not occurred during night time. No history of trauma or underlying disease was reported. He practiced taekwondo as a hobby. Blood test results revealed no abnormalities, such as systemic disease or evidence of pyogenic coxitis.

Radiographs showed a sclerotic line along the left femoral neck and evidence of callus formation. A minute disruption of the medial cortex at the trochanteric area was detected on the right side (Fig. 1). A magnetic resonance imaging (MRI) was taken to help with the 


\section{Hip \& Pelvis}

Hip Pelvis 28(3): 169-172, 2016

diagnosis, and T1-weighted images showed decreased signal intensity along the left femoral neck and on the medial cortex of the right femur. T2-weighted images showed high signal intensity in the same area (Fig. 2).

The patient underwent conservative treatment with wheelchair ambulation and bed rest for 2 weeks. After 2 weeks, which was 6 weeks from the start of pain, he felt diminished bilateral hip pain and radiographs showed more sclerosis along the bilateral femoral neck, since then, partial weight-bearing ambulation with two crutches was permitted (Fig. 3A). Ten weeks from the start of pain, he did not complain of any discomfort and showed full ROM bilaterally. Radiographs indicated nearly complete bony union at the previous fracture site
(Fig. 3B). Radiographs obtained 4 and 12 months after the initial pain developed showed complete healing of the stress fracture (Fig. 4).

\section{DISCUSSION}

Femoral neck stress fractures in children were first reported by Devas ${ }^{3)}$ in 1963 . He classified these fractures into two groups according to radiographs. The compression type, which account for most of stress fractures in children, typically show inferomedial cortical disruption initially, whereas a transverse type fracture, also known as tension type, tend to appear at the superolateral cortex ${ }^{5}$. Up to now, only one case of a
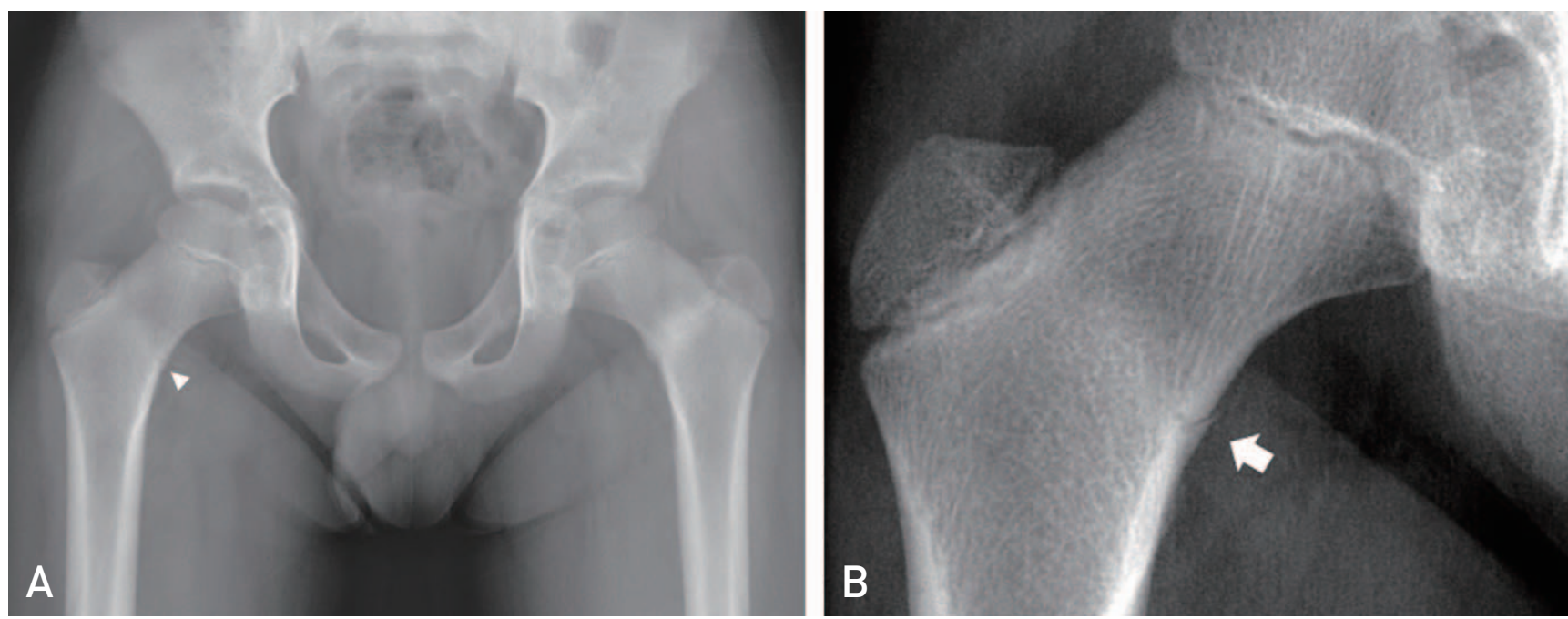

Fig. 1. Radiographs were obtained at 4 weeks from the start of pain. (A) Antero-posterior radiographs of the hip joint showed sclerotic line along the left femoral neck (arrowhead). (B) Close-up of right femoral neck showed inferomedial cortical interruption which was typically seen in compression type of fracture by Devas classification (arrow).
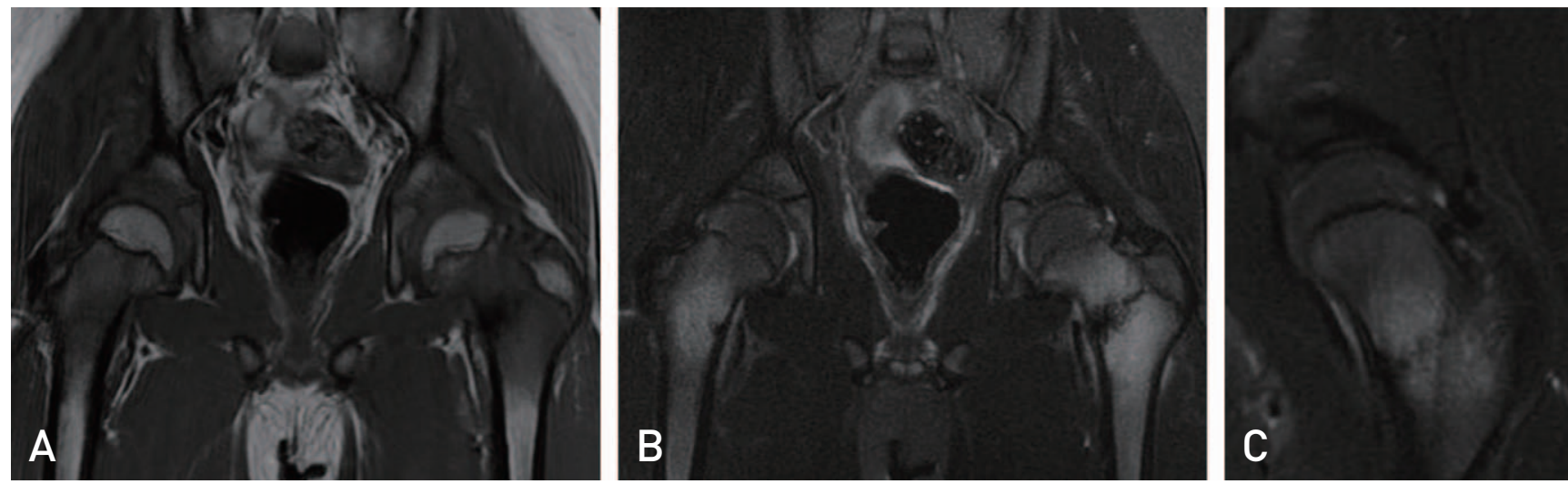

Fig. 2. (A) Stress fracture of the left femoral neck indicated low signal intensity in T1-weighted image. (B) T2-weighted image showed fracture line along the left femoral neck and interruption of cortex at inferomedial portion of the right femoral neck. (C) Sagittal T2-weighted image of the right femoral neck. 


\section{Hip \& Pelvis}

Gun-Woo Lee et al. Bilateral Femoral Neck Stress Fracture in Child
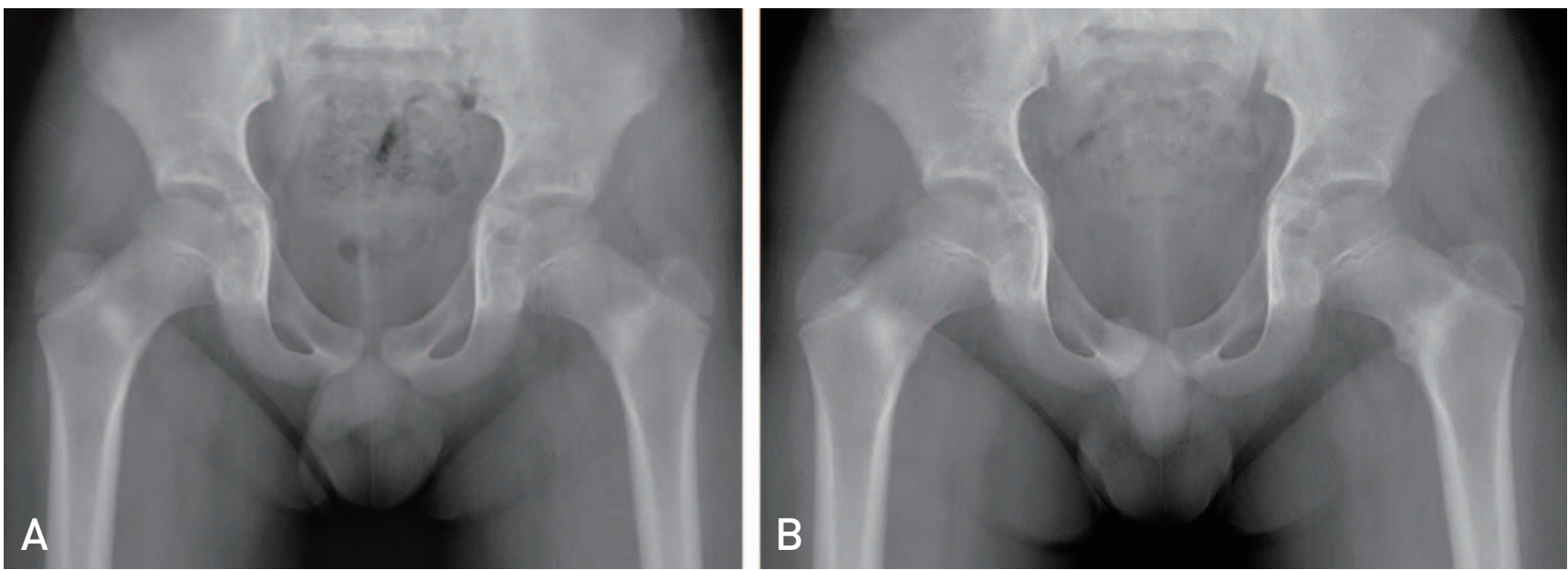

Fig. 3. (A) Radiograph, 6 weeks after the onset of pain, showed callus formation along the bilateral femoral neck. (B) After 10 weeks from the initial pain, radiograph demonstrate nearly complete bony union bilaterally.
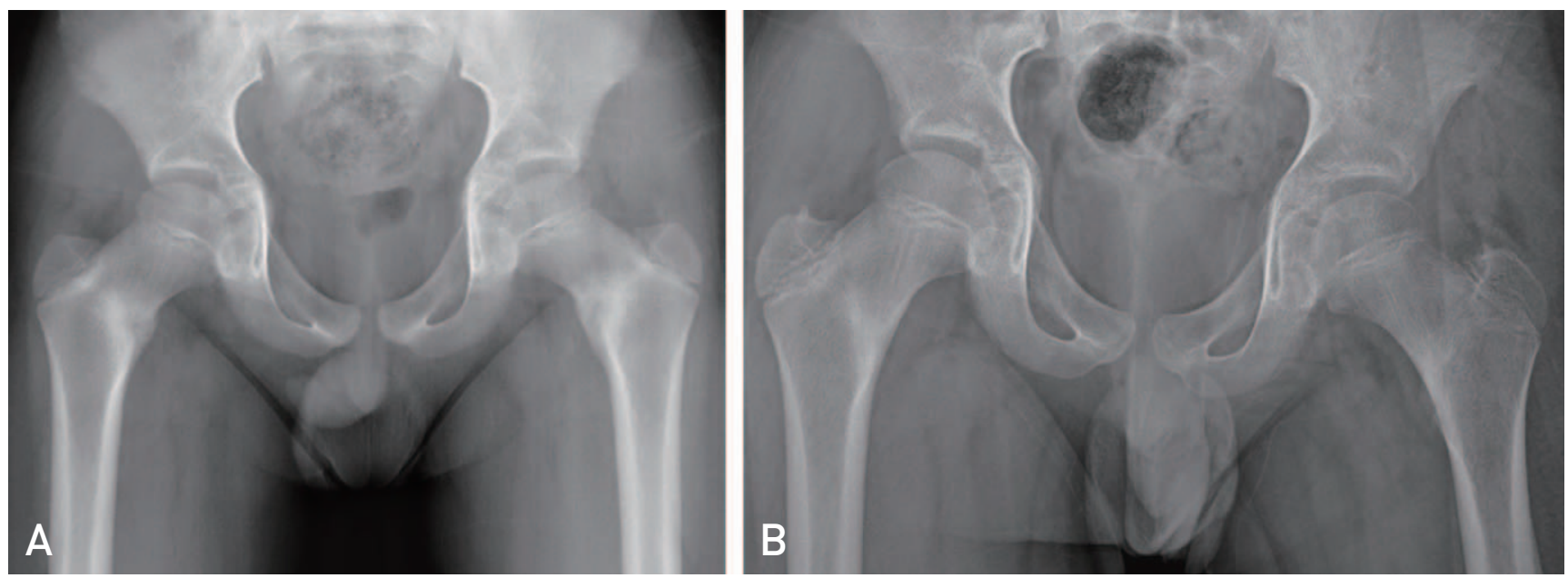

Fig. 4. Radiographs obtained 4 months (A) and 12 months (B) after the initial pain developed.

bilateral femoral stress fracture has been reported in a child ${ }^{6}$.

The common symptoms of previously described cases were sustained hip pain and limping. Some cases had a history of excessive sports activity and problems affecting general health condition, such as anorexia nervosa ${ }^{2,7)}$, whereas others had no clear contributory factors ${ }^{4,8}$. Our patient had no history of trauma or medical problems.

Radiographs are initially used to diagnose disease. However, in early stage of injury, it is difficult to detect a femoral neck stress fracture because of its nondescript features on radiographs. A few weeks after injury, it tend to appear as radiolucency through the cortex without any periosteal reaction. After two to eight weeks from the onset of symptoms, periosteal reaction or callus formation are generally seen as a result of bone remodeling ${ }^{9)}$. However, MRI makes early diagnosis possible for patients who have clinical suspicion for stress fracture but radiographs are negative. Early resorption of bone can be manifested as local hyperemia and edema along the endosteal surface on MRI. Fatsuppressed T2-weighted images are important for detecting edema of the bone marrow. Several weeks after injury, a MRI shows bone marrow edema on both T1- and T2-weighted images and signal changes in the cortical bone. The common pattern of stress fracture on MRI is a low signal intensity line, surrounded by illdefined large edema. The diagnosis of stress fracture was based on the presence of a focal, cortical and medullary zone of increased radionuclide uptake in all phases of bone scintigraphy. Although false-negative 
cases have been reported, bone scintigraphy has been considered as gold standard for early detection of stress fracture $^{9,10}$.

The cortical interrupted region differs in compression (inferomedial) and tension types (superolateral) of femoral neck stress fractures. According to this classification, most fractures are the compression type and the remainder are tension type ${ }^{5)}$. Given past experience, a compression type fracture usually does not require internal fixation and conservative treatment with limited weight-bearing is sufficient for healing ${ }^{6}$. However, an increased risk of displacement and a potential increase in osteonecrosis of the femoral head can occur in tension type fractures. Thus, patients with a tension type fracture must undergo internal fixation ${ }^{5)}$. Differential diagnoses include hip joint strain, synovitis, osteoid osteoma, Legg-Calvé-Perthes disease, slipped capital femoral epiphysis, and malignant conditions such as osteosarcoma.

Because a femoral neck stress fracture is rare, it is easy to overlook in the differential diagnosis or may be misdiagnosed. Femoral neck stress fractures in children can be difficult to diagnose on plain radiographs. Thus, a femoral neck stress fracture should be considered in the differential diagnosis in children who present with sustained hip or groin pain, and MRI, close follow-up with serial radiographs should be performed.

\section{CONFLICT OF INTEREST}

The authors declare that there is no potential conflict of interest relevant to this article.

\section{REFERENCES}

1.Devas MB. Stress fractures of the femoral neck. J Bone Joint Surg Br. 1965;47:728-38.

2. Moroney P, O'Connor PA, Ali W, Brady OH. Stress fracture of the femoral neck in a 24-year-old female with anorexia nervosa induced osteoporosis. Ir Med J. 2007; 100:542-3.

3. Devas MB. Stress fractures in children. J Bone Joint Surg Br. 1963;45:528-41.

4. Fiévez EF, Hanssen NM, Schotanus MG, van Haaren EH, Kort NP. Stress fracture of the femoral neck in a child: a case report. J Pediatr Orthop B. 2013;22:45-8.

5. Er MS, Eroglu M, Altinel L. Femoral neck stress fracture in children: a case report, up-to-date review, and diagnostic algorithm. J Pediatr Orthop B. 2014;23:117-21.

6. Scheerlinck T, De Boeck H. Bilateral stress fractures of the femoral neck complicated by unilateral displacement in a child. J Pediatr Orthop B. 1998;7:246-8.

7. Azouz EM, Karamitsos C, Reed MH, Baker L, Kozlowski $\mathrm{K}$, Hoeffel JC. Types and complications of femoral neck fractures in children. Pediatr Radiol. 1993;23:415-20.

8. Román M, Recio R, Moreno JC, Fuentes S, Collantes F. Stress fracture of the femoral neck in a child. Case report and review of the literature. Acta Orthop Belg. 2001;67: 286-9.

9. Tins BJ, Garton M, Cassar-Pullicino VN, Tyrrell PN, Lalam R, Singh J. Stress fracture of the pelvis and lower limbs including atypical femoral fractures-a review. Insights Imaging. 2015;6:97-110.

10. Kiuru MJ, Pihlajamaki HK, Hietanen HJ, Ahovuo JA. MR imaging, bone scintigraphy, and radiography in bone stress injuries of the pelvis and the lower extremity. Acta Radiol. 2002;43:207-12. 